\title{
Lung Mucous Gland Adenoma
}

National Cancer Institute

\section{Source}

National Cancer Institute. Lung Mucous Gland Adenoma. NCI Thesaurus. Code C5664.

A benign adenomatous neoplasm that arises from the mucous glands in the bronchus. 